\title{
ERRATUM
}

\section{Comparative Education Research: Approaches and Methods}

\author{
Mark BRAY, Bob ADAMSON \& Mark MASON
}

M. Bray et al. (eds.), Comparative Education Research: Approaches and Methods, CERC Studies in Comparative Education 19, DOI 10.1007/978-3-319-05594-7,

(C) Springer International Publishing Switzerland 2014

DOI 10.1007/978-3-319-05594-7_16

Volume number in the original version of this book was inadvertently published an incorrect number ' 32 ' throughout the book.

The correct volume number is 19 . 